\title{
EVALUATING MOTIVATION OF CONSTRUCTION WORKERS: A COMPARISON OF FUZZY RULE-BASED MODEL WITH THE TRADITIONAL EXPECTANCY THEORY
}

\author{
Muluken YEHEYIS ${ }^{\mathrm{a}}$, Bahareh REZA ${ }^{\mathrm{a}}$, Kasun HEWAGE ${ }^{\mathrm{a}}$, \\ Janaka Y. RUWANPURA ${ }^{\mathrm{b}}$, Rehan SADIQ ${ }^{\mathrm{a}}$ \\ aUniversity of British Columbia, Okanagan Campus, 1137 Alumni Avenue, Kelowna, BC Canada \\ ${ }^{b}$ University of Calgary, 2500 University Drive, NW, Calgary, AB Canada
}

Received 10 Apr 2013; accepted 12 Nov 2013

\begin{abstract}
Measuring workers' performance and the level of motivation is of paramount importance as the productivity of workers at a workplace primarily depends upon their level of motivation. However, measuring the level of workers' motivation at workplace is not always straightforward because the workers' motivation is a function of various personal and external factors. This paper proposes a fuzzy rule-based model for evaluating the motivation level of construction workers using their working patterns. The motivation level evaluated using the fuzzy rule-based model was compared with motivational levels determined by the traditional Vroom's expectancy theory or Expectancy-Instrumentality-Valence (EIV) method. EIV method used questionnaire surveys and interviews to determine workers' motivation. The results of fuzzy rule-based models aligned closely with the EIV model, especially for the middle range of motivation levels. Compared to traditional EIV model, the fuzzy rule-based system is simple to implement and found to be very pragmatic in construction field settings.
\end{abstract}

Keywords: worker motivation, construction productivity, expectancy theory, fuzzy set theory, fuzzy rule-based model.

\section{Introduction}

The construction industry is an important industrial sector that plays a vital role in the national economy including Canada and the rest of North America due to the usage of its end products such as roads, buildings, dams etc. However, decline of construction productivity in North America has been reported by many researchers over the past decades (Choy, Ruwanpura 2006; Hewage, Ruwanpura 2006, 2009; Song, AbouRizk 2008). There are many factors which contribute to the decline in construction productivity including low worker motivation, inadequate communication, unclear instructions, worker fatigue, poor materials and tools management standards, poor relations between workers and management, poorly organized projects, unfair work assignments, incomplete design/engineering work, lack of cooperation among different crafts, poor supervision, rework, no worker participation in the decision-making process, restrictive and burdensome procedures, and so on (Hewage 2007).

A major portion of construction budget, about 25$40 \%$ of the project capital cost, is allocated to labour expenses (Nasirzadeh, Nojedehi 2012; Ng et al. 2004). Many recent researches emphasize on the fact that labour force plays a crucial role in the construction process, thus there is a need to maximize the productivity of labour re- sources (Jergeas, Ruwanpura 2009; Nasirzadeh, Nojedehi 2012; Ng et al. 2004). Therefore, it is very important to find solutions for declining construction productivity in terms of labour issues that may save billions of dollars and make construction an attractive business.

Productivity has many definitions based on selected performance factors such as production rate, unit person hour rate, etc. In the context of construction, however, project managers and construction professionals recognize productivity as an in-place value divided by inputs, such as work hours (Hanna et al. 2005; Nasirzadeh, Nojedehi 2012). High productivity refers to the intensive and/or efficient use of scarce resources converting inputs into outputs, which ultimately lead to more profit (Arditi 1985; Dai et al. 2009). Some argue that the productivity can be achieved/increased by working harder, faster, or longer. However, in the real world, productivity cannot be achieved by only speed and hard work without adopting the best management and work practices (Banik 1999). Even with the advent of more sophisticated technology, the construction industry continues to be predominantly labour-intensive, suggesting for the need to give proper emphasis to such matters like communications, participation, and motivation (Hwang, Liu 2010; Mansfield, Odeh 1991). 


\section{Background}

\subsection{Motivation as a tool for improving productivity}

Motivation has a wide variety of definitions. According to Jenkins et al. (1982), motivation is intangible: a hypothetical construct that is used to explain human behaviour. Motivation can be either intrinsic or extrinsic. Intrinsic motivation is generated by a factor that comes from within the subject (self-actualisation, satisfaction, more individual control). Extrinsic motivation is generated by a factor that comes from the exterior (e.g. pay increase, promotion, quality awards, etc.).

Recently, Westover et al. (2010) conducted a research to explore 17 key work domains that impact workers' productivity and motivation. Both recent and earlier researches in the construction industry have revealed that productivity and motivation are interdependent (Rose, Manley 2011; Warren 1989).

The imperative need of discovering, comprehending, and implementing employee motivation has been a principal concern for organizations, managers, and even first line supervisors because employee motivation has been and will be the deciding factor in work performance which lead to the success or failure of an organization (Dongho 2006). Consequently, considerable research has been reported on the relationship between motivation and productivity in the construction industry over the last 40 years (Edwards et al. 2007; Hewage 2007; Love et al. 2005; Olomolaiye, Price 1998; Zhou 2004).

In an earlier research Maloney and McFillen (1987) conducted a comprehensive research study on construction labourers' motivational patterns, which focused on the importance attached to various job-related factors and their satisfaction over each factor. Further, they said that the motivation has a direct impact on the work performance, and it can be positively influenced or managed by external factors, such as incentives and rewards.

Zhou (2004) conducted a research on motivating construction management professionals and indicated that motivation, when it is combined with work experience and education, is an important factor in improving performance and thus productivity. Hewage (2007) studied fifty one factors affecting productivity and prioritized those factors into nine categories. In that research motivation ranked the second important factor affecting the workers' productivity. Accordingly, motivators should be of a great concern to managers in construction organizations, as the proper implementation of motivational programmes can encourage employees to act in the desired way to accomplish the organization's goals at the same time as they meet their own personal objectives or motives (Mansfield, Odeh 1991).

Theories of motivation are not discussed in detail in this paper, as such information already available in literature. Hewage (2007) provided one such review, which clearly outlined the origins of motivation theories that applied to study construction workers. Hewage (2007) explained several theories available to present the con- cept of motivation. The list includes Maslow's Hierarchy of Needs Theory (Huitt 2004; Maslow 1943), Herzberg Motivational Theory (Herzberg et al. 1959), Mcgregor's theories X and Y (McGregor 1960), Adams' Equity Theory (Adams 1963), Vroom's expectancy theory (Vroom 1964), Brehm's Reactance theory (Brehm 1966), Locke's Goal theory (Locke 1968), Reinforcement Theory (Skinner 1969), Alderfer's ERG Theory (Alderfer 1969), and Ouchi's theory of Z (Ouchi 1981). Detailed definitions, background information, and other related issues of these theories can be also found in Jang et al. (1997), Latham and Pinder (2005).

This research mainly aims to demonstrate the application of the expectancy theory of Vroom (1964) to quantify motivation in the construction industry. Several new researches used and improved the expectancy theory in different management extents. Chiang and Jang (2008) applied a modified expectancy theory with five components to investigate employee motivation in the hotel setting and confirmed the validity of expectancy theory. Gorges and Kandler (2012) examined the applicability of expectancy-value theory to adults' learning motivation. Kominis and Emmanuel (2007) investigated the relationship between managerial perceptions of elements of the performance measurement, evaluation and reward system, and motivation. They developed an extended version of the traditional expectancy-valence model to conceptualise the process of motivation at the middle management level.

There is a strong history of researchers who explored motivational expectancy theories in a wide variety of formats, including case studies. Yet, too few have focused their work specifically on construction workers. Among formerly researches Maloney and McFillen $(1986,1987)$ conducted a research to study operational construction employee motivation amongst union members in America. They determined that the expectancy theory is a workable conceptual base for understanding the motivation of construction workers (Maloney, McFillen 1986). They conclude that application of expectancy theory principles to construction work pinpoints significant areas for action if construction workers are motivated towards higher productivity (Maloney, McFillen 1986).

In more recent works Lam and Tang (2003) review key motivation concepts, and describes how to apply the theory into practice in construction projects. The authors offered a viewpoint with both short-term and long-term motivation schemes. Price et al. (2004) presented empowerment as the key tool to motivate the workforce. The researchers suggested that culture, training, and knowledge management lead to workers empowerment through incentive, thus motivate the workforce, and ultimately improve construction performance.

Hewage and Ruwanpura (2006), Hewage (2007) applied Vroom's expectancy theory as the bases to quantify construction worker motivation. They investigated work- 
er motivation and productivity, which are under human issues. They overcame the challenge of quantification of motivation by using Vroom's motivational expectancy theory with other "construction" applicable theories such as equity theory, Herzberg's hygiene theory, and reinforcement theory. The background information on expectancy theory is provided below.

The expectancy theory of motivation (also called the Expectancy-Instrumentality-Valence (EIV) model) is a theory explaining the process of individuals' decisions on various behavioural alternatives. To relate performance to motivation in a mathematical form, Vroom (1964) defined the performance $(\mathrm{P})$ as a function of the product of motivational force (M) and workers' ability (A), i.e., $P=f(M . A)$. Expectancy theory suggests that motivation depends on individuals' expectations on their ability to perform tasks and receive desired rewards. Expectancy theory can be expressed using following equation:

$$
\text { Motivation }=f \sum(E \rightarrow P) \times(P \rightarrow O) \times V,
$$

where: $E \rightarrow P$ - Effort to performance expectancy (Expectancy); $P \rightarrow O$ - Performance to outcome expectancy (Instrumentality); and $V$-Valence.

Effort to Performance expectancy $(E \rightarrow P)$ is the belief that effort leads to a desired performance level. In other words, workers tend to perform more if they believe in and feel confident about their efforts. Performance to Outcome expectancy $(P \rightarrow O)$ is the belief that performance will be followed by the desired outcome. Valence is the preference or appreciation of the outcomes or end results.

Vroom's expectancy theory has been selected for this study because (i) this theory is based on the relationship between the individual's effort, individual's performance, and the desirability of outcomes associated with high performance, (ii) this theory provides a general framework for assessing, interpreting, and evaluating employee behaviour in learning, decision-making, attitude formation, and motivation, (iii) this theory has been rigorously tested and has received strong support (Fudge, Schlacter 1999), and (iv) this theory would seem most applicable to the construction work in which motivation level of employees depends on either they want the reward on offer for doing a good job or if they believe more effort will lead to that reward (Hewage, Ruwanpura 2006).

\subsection{Fuzzy rule-based model (FRBM) for evaluating motivational force}

Subjective (asking workers about their perceptions of motivation and what influences it) or objective measures (directly observing factors such as timeliness, or checking attendance records) have been widely used to measure the performance and the level of employees' motivation (Bennett et al. 2001). Questionnaire and interview sur- vey techniques are also frequently used in the construction management field (Lyons, Skitmore 2004; Mangione 1995). However, the questionnaire and interview survey techniques have limitations. The major limitation of the survey method is that it relies on a self-reporting method of data collection. Intentional deception, poor memory, or misunderstanding of the questions, all can contribute to inaccuracies in the data (Trochim, Donnelly 2007). Questionnaires usually have low response rates, require longer time periods, and are more affected by self-selection, lack of interviewer involvement, and lack of open-ended questions. Similarly, interviews are labour-intensive, time-consuming and expensive, and it requires trained interviewers. Collecting data through survey methods is also an imposition if it does not benefit the individual surveyed. Likert scales are widely used in these survey questions to elicit preferences or evaluations (Gob et al. 2007; Tsaur et al. 2000). However, due to intangible and subjective information often appearing in the evaluation process, crisp values in traditional Likert scale are inadequate to present the evaluation ratings of interviewees (Hu et al. 2010; Lalla et al. 2004). Some of the problems associated with the Likert scale method include: (1) social desirability bias, i.e. tendency to provide responses that the respondent believes are those which make him or her "look good"; (2) acquiescence bias, i.e. the tendency to agree rather than disagree with any statement; (3) central tendency bias, i.e. the tendency to respond towards the center of the response scale (Lalla et al. 2004).

Fuzzy logic model, also known as fuzzy inference system or fuzzy rule-based model, is a logical-mathematical procedure based on fuzzy set theory (Zadeh 1965) that is considered suitable for dealing with many real world problems, characterized by complexities, uncertainties, and a lack of knowledge of the governing physical laws (Kumar et al. 2007). Fuzzy logic extends the general form of Boolean logic, true and false to handle the concept of vagueness and uncertainty. This approach takes a value between 1 (full belongingness) and 0 (no belongingness), rather than a crisp value. The degree of belongingness is called the membership function (Erinawati, Fenton 2004). This characteristic allows capturing the uncertainty inherent to real data.

A typical fuzzy logic system consists of three major components: fuzzification, fuzzy inference, and defuzzification. Fuzzification comprises the process of transforming crisp values into grades of membership for linguistic terms of fuzzy sets. The membership function is used to associate a grade to each linguistic term (Kramer et al. 2009). The shape of membership functions of fuzzy sets can be triangular, trapezoidal, bell-shaped, sigmoidal, or another appropriate form, depending on the nature of the system being studied (Sadiq et al. 2004). Among them, triangular and trapezoidal shaped membership functions are predominant in current applications of fuzzy set theory, due to their simplicity in both design and implementation based on little information (Rihani et al. 2009). 
The second step, fuzzy inference is a process of formulating a mapping from inputs to output using fuzzy logic. A fuzzy inference system is composed of fuzzy if-then rules relating different fuzzy sets (linguistic constants), which are stored in a knowledge-base, and an inference engine that performs approximate reasoning (Ross 2004). Finally, in defuzzification, the linguistic results obtained from the fuzzy inference are translated into a real crisp value (Ross 1995). This phase is responsible for transforming the fuzzy results from the fuzzy system into crisp values (Kusan et al. 2010). There are several defuzzification methods, such as the max-membership, center of gravity, weighted average, mean-of-maxima membership, center of sums, center of the largest area, and first or last of maxima methods (Ross 1995). Among all these methods, center of area method is used in most of the applications.

Fuzzy logic has been successfully applied in virtually all areas of engineering and computer sciences, as well as in areas of decision making, optimization, management, and operations research (Klir, Yuan 1995). Some advantages of fuzzy logic and fuzzy inference system recently stressed in different research areas (e.g., Hajkowicz, Collins 2007; Islam et al. 2013; Jaramillo, González 2009; Lermontov, Yokoyama 2009). These advantages include, but not limited to: (1) developing a clear mathematical model; (2) describing nonlinear relationships using simple rules; (3) formalizing the reasoning process of human language using fuzzy logic; and (4) incorporating expert opinions with real data (Chang et al. 2001; Islam et al. 2013).

According to Fayek and Flores (2010), fuzzy logic has been used in construction industry for risk assessment (Tah, Carr 2000; Nasirzadeh et al. 2008), range estimating (Shaheen et al. 2007), predicting and diagnosing construction performance (Dissanayake, Fayek 2008), assessing working conditions (de Vries, Steins 2008), contractor selection (Bendaña et al. 2008), and determining cost estimating relationships (Mason, Kahn 1997). However, there are limited studies on the use of fuzzy logic to predict and evaluate the performance and motivational levels of workers in construction industry.

This paper aims to indicate the application of fuzzy rule-based model, with observed working patterns of workers, as a tool to evaluate the motivation levels of workers in the construction industry. In addition, this research also involves the following sub-objectives: (i) evaluation of motivation of the construction workers using the expectancy theory based on the survey research method (questionnaire survey) and (ii) application of fuzzy-Likert scale to quantify and analyse questionnaire survey data collected by traditional Likert method to improve the evaluation of workers' motivation using expectancy theory.

\section{Research methodology}

This section provides a brief overview of the methodological consideration and approach of the study. It describes the data collection methods and outlines the expectancy theory and fuzzy inference methods of evaluating motivation and productivity of construction workers.

\subsection{Evaluation of worker motivation using expectancy theory (EIV model)}

\subsubsection{Questionnaire survey}

A questionnaire survey was used to collect data for evaluating motivation of construction workers using the EIV model. The questionnaire surveys were anonymous. The researcher assigned a number to each worker and asked the project coordinator to pick a number. Neither the worker nor the coordinator were aware of the assigned numbers to individual workers. Workers (research subjects) were selected for interviews and questionnaire surveys on a random and voluntary basis. An "anonymous" questionnaire was given to the selected participant after a short interview.

Observation of a given worker were conducted on the same day after the project coordinator picked a number (worker). Worker was not aware of individual "observation". However, all the workers were informed (in general) of potential "observations", in the given research period, in a particular construction project. Observations were used to verify the views expressed in the interview against the observed working patterns. The format settled for observation was a 30 minute observation in the morning, followed by the interview conducted after the morning coffee break (usually at 9:45 am), and then 30 minutes of observation of the same worker in an afternoon of a different day. As mentioned above, the research subjects were not aware of individual observation focuses of a given time. In addition, the observation was conducted from a distant location to minimize the disturbances to construction workers.

A total of 101 workers from four projects were interviewed, observed, and then invited for participating in the survey (information regarding sample size validity has been provided in Appendix). The authors had several discussions with social science research methods experts (professors) and psychology doctoral students to verify the face validity of the intended research tools (interview and observation). Face validity was based on the rational judgment of the researchers and experts (whether or not an object is truthful about what is saying and/or behaving) to indicate the appropriateness of a measurement instrument to measure a given phenomenon. The researchers were well satisfied with the methods employed during the direct observation and interview conducted to measure the intended phenomena. All participants of the survey were allowed to take questionnaire home for completion and return later. Answering to the questionnaire survey was optional and on a voluntary basis in order to assure the truthfulness of the survey responses.

Out of 101 interviewed and observed workers, 39 workers returned the responses, representing 39\% response rate. Of the 39 returned responses, one was not 
usable due to substantial missing information. Thus, remaining 38 responses were used for the analysis. The construction workers who participated in the survey included carpenters, carpentry foremen, and carpentry helpers working in various construction activities including formwork, false work (the supporting structure for formwork such as jacks and props), and columns. The background information of participants in the questionnaire survey is summarized in Table 1. Detailed information on the type and nature of survey questions and the background information of participants in the questionnaire survey were presented in Hewage (2007).

The questions of the survey were divided into three sections: two questions designed to measure the worker's beliefs about the possibility of certain outcomes when working in the construction; 23 questions related to instrumentality designed to measure the possibility of getting certain rewards attainable while working in the construction site; and 23 questions related to valence designed to measure the importance of each outcome that might result from working in construction site. These questions were answered on a seven-point Likert scale ranging from $1=$ strongly disagree to $7=$ strongly agree as shown in Table 2.

Table 1. Profile of respondents

\begin{tabular}{lcc}
\hline \multirow{2}{*}{ Profile } & \multicolumn{2}{c}{ Total number $=38$} \\
\cline { 2 - 3 } & $\mathrm{N}$ & $\%$ \\
\hline Gender & 38 & 100 \\
\hline Male & & \\
\hline Education & 2 & 5.3 \\
\hline Primary School/Intern & 12 & 31.6 \\
\hline High school degree & 4 & 10.5 \\
\hline Completed some college & 13 & 34.2 \\
\hline Technical College or university & 7 & 18.4 \\
\hline No response & & \\
\hline Department & 18 & 47.4 \\
\hline Carpenters & 11 & 28.9 \\
\hline Foremen/Surveyors & 3 & 7.9 \\
\hline Labours & 6 & 15.8 \\
\hline No response & & \\
\hline Year of experience & 13 & 34.2 \\
\hline 10 years and below & 12 & 31.6 \\
\hline $11-20$ years & 6 & 15.8 \\
\hline 20 years and above & 7 & 18.4 \\
\hline No response & &
\end{tabular}

\subsubsection{EIV model and data analysis}

The motivation $(M)$ of the construction workers using expectancy theory is evaluated by using Eqn (2):

$$
M=\sum E \times I \times V
$$

where: $M$ - Motivation, $E$ - Expectancy, $I$ - Instrumentality and $V$ - Valence.
Because of the limitations of traditional Likert scale (crisp value) discussed in the introduction section of this paper, both traditional Likert scale and fuzzy-Likert scale were used for the questionnaire data in the EIV model. First, each crisp Likert scale was normalized within the range of $1 / 7$ to 1 as shown in Table 2 . Then the fuzzyLikert scales were obtained by transforming every element of the discrete normalized Likert scale to a Fuzzy set using Eqn (3). Triangular fuzzy membership was used for simplicity although the selected shape should be justified by available information (Guyonnet et al. 1999):

$$
\mu\left(L_{N}, x\right)=\left\{\begin{array}{ll}
1-7\left|L_{n}-x\right|, & \text { if }|L-x| \leq \frac{1}{7}, \\
0, & \text { otherwise }
\end{array},\right.
$$

where: $\mu$ (LN, $\mathrm{x})$ - the membership function of the fuzzyLikert scale, and LN - normalized crisp Likert scale.

Table 2. Description of Likert scale and assumption of fuzzy numbers

\begin{tabular}{lccc}
\hline Linguistic Variables & $\begin{array}{c}\text { Likert } \\
\text { scale }\end{array}$ & $\begin{array}{c}\text { TFN } \\
\text { representation }\end{array}$ & $\begin{array}{c}\text { Normalized } \\
\text { TFN values }\end{array}$ \\
\hline $\begin{array}{l}\text { Strongly disagree / } \\
\text { Very low }\end{array}$ & 1 & {$[0,0,1]$} & {$[0,0,1 / 7]$} \\
\hline Disagree / Low & 2 & {$[1,2,3]$} & {$[1 / 7,2 / 7,3 / 7]$} \\
\hline $\begin{array}{l}\text { Somewhat disagree / } \\
\text { somewhat low }\end{array}$ & 3 & {$[2,3,4]$} & {$[2 / 7,3 / 7,4 / 7]$} \\
\hline Neutral / Average & 4 & {$[3,4,5]$} & {$[3 / 7,4 / 7,5 / 7]$} \\
\hline $\begin{array}{l}\text { Somewhat agree / } \\
\text { Somewhat high }\end{array}$ & 5 & {$[4,5,6]$} & {$[4 / 7,5 / 7,6 / 7]$} \\
\hline Agree / High & 6 & {$[5,6,7]$} & {$[5 / 7,6 / 7,1]$} \\
\hline $\begin{array}{l}\text { Strongly agree / } \\
\text { Very high }\end{array}$ & 7 & {$[6,7,7]$} & {$[6 / 7,1,1]$} \\
\hline
\end{tabular}

\subsection{Modelling worker motivation using FRBM}

The proposed fuzzy rule-based model used observation data (working time distribution) to evaluate the motivation level of workers in construction industry. In this study, all 38 workers who returned the questionnaires were continuously observed twice: 30 minutes in the morning shift and 30 minutes in the afternoon shift, to measure working time (tool time) and other time spent on different activities. During the observation data collection, the time spent for construction activities by each worker was divided into two main categories: working (tool time) and non-working time. The non-working time is further divided into seven sub-categories: materials searching time, tools searching time, socializing time, moving time, instructions time, idle, and time for others.

\subsubsection{Variable selection}

If all these eight time categories were described by three linguistic descriptors/constants (i.e., three membership functions), then $3^{\wedge} 8=6561$ rules would be required to develop a FRBM. According to Gallo et al. (1999) and Dubois and Prade (1980), the development of fuzzy inference system characterised by a large number of input 
variables (more than five or six), appears very difficult especially in knowledge engineering in order to specify the real input variables, the relative relations, such as the consequent complexity of the knowledge base. Bendaña et al. (2008) applied fuzzy-logic-based systems for evaluating different qualitative and quantitative criteria for selecting contractors. They established specific ways to facilitate working with higher numbers of input variables.

In construction environment, the amount of working time has a direct impact on the Output (Choy, Ruwanpura 2006). Choy and Ruwanpura (2006) indicated that the relationship between working time and output can be expressed as the efficiency, which is the amount of work done per unit of the working time, not the total time. Accordingly, in the current study, workers' time spent on construction activities were divided into two main categories: working and non-working time. Non-working time consists of activities such as looking for materials and tools, idling, socializing, and moving. Table 3 shows all the observed time categories.

Table 3. Working patterns of construction workers and observational categories

\begin{tabular}{ll}
\hline \multicolumn{1}{c}{ Category } & \multicolumn{1}{c}{ Definition } \\
\hline $\begin{array}{l}\text { Work (tool) } \\
\text { time }\end{array}$ & Direct effective working time. \\
\hline $\begin{array}{l}\text { Looking for } \\
\text { materials }\end{array}$ & $\begin{array}{l}\text { Time spent on searching, waiting, or moving } \\
\text { materials from another place away from } \\
\text { individual's working area. }\end{array}$ \\
\hline $\begin{array}{l}\text { Looking for } \\
\text { tools }\end{array}$ & $\begin{array}{l}\text { Time spent on searching, waiting or } \\
\text { moving tools from another place away from } \\
\text { individual's working area. }\end{array}$ \\
\hline Socializing & $\begin{array}{l}\text { Socializing or chatting time on top of the } \\
\text { assigned breaks. }\end{array}$ \\
\hline Moving & $\begin{array}{l}\text { Moving around the site without performing } \\
\text { anything related to the given work. }\end{array}$ \\
\hline Instructions & $\begin{array}{l}\text { The time spent for receiving or giving } \\
\text { instructions. }\end{array}$ \\
\hline Idle & $\begin{array}{l}\text { Time spent in construction site without } \\
\text { performing anything related to the assigned job. }\end{array}$ \\
\hline Other & $\begin{array}{l}\text { Moving away from the working/observational } \\
\text { area, staying near heaters, or something not } \\
\text { mentioned in above categories. }\end{array}$ \\
\hline
\end{tabular}

Based on the observation results, the average effective working time (tool time) of of observed workers was $47.7 \%$, as shown in Figure 1. This does not mean the workers were engaged in non-work related activities for the remaining $52.3 \%$ of the non-tool time. Non-tool time consists of some supporting activities such as material handling and instructions. The largest portion of non-tool time in Figure 1 is "looking for materials" (definition in Table 3). When workers were looking for materials, it led to other interruptions such as stopping at several other places, chatting, and smoking. On many occasions, it was observed that workers and foremen did not plan for material requirements based on work progress or the work targets of the day. As a result, workers had

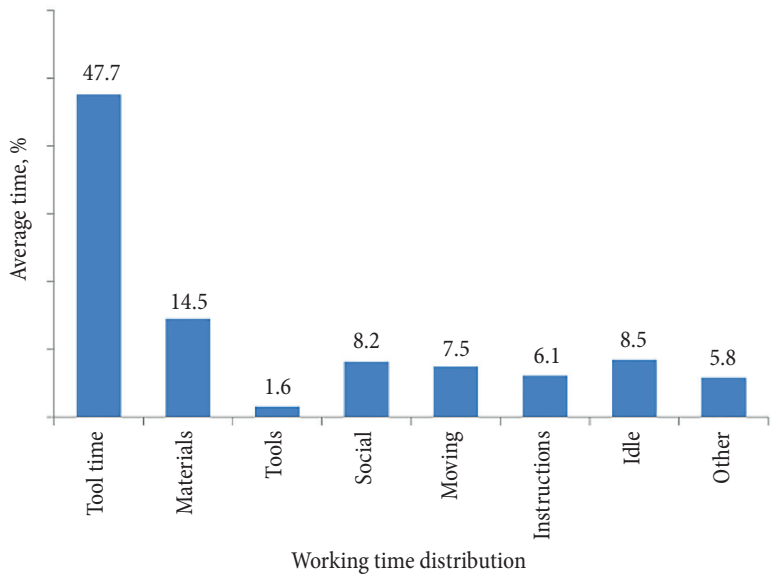

Fig. 1. Working time distribution of the 38 construction workers

to deal with the immediate demands of issues related to materials. "Idling" was the second largest portion of nonworking time. Construction workers spent about $8.2 \%$ of their "total working time" for socializing. Based on the observation results, some workers tend to use working time as a socializing time. However, observers couldn't identify any direct relationship between social time and motivation level of individual workers.

In this research, four out of eight variables with observable effects on lowering/increasing the workers' motivation were selected. A detailed analysis of working efficiencies and the working patterns of construction workers was presented by Hewgae (2007). In addition, Choy and Ruwanpura (2006) discussed the impacts of non-tool time on other time categories in detail. The four selected worker time distributions are tool time, time for looking tools, time for looking materials, and idle time. The working (tool) time is the direct effective working time. It is directly related to worker's efficiency (performance) and automatically considered as input variable. The effective working (tool time) time of all 38 construction workers included in this study is the largest portion of the time distribution, as shown in Figure 1. Similarly, the time for searching materials that refers to the time spent on searching, waiting, or moving materials from another place away from individual's working area was the largest portion of non-tool time. Searching for tools is the time spent on searching, waiting, or moving tools from another place away from individual's working area. The time for searching materials and the time for searching tools were combined together and considered as a single input (variable) in the proposed FRBM. Hence, three input variables used in fuzzy rule-based models are working (tool) time, materials and tools searching time, and an idle time.

Other time variables with imprecise observable effects on motivation, i.e. social time, moving time, and instruction times, were eliminated. This means that the observers couldn't identify any distinct relationship between these time variables and workers' motivation. 
It is necessary to mention that none of the existing engineering literature reported a behavioral study on construction workers to identify direct or indirect correlation between these eliminated time variables and motivation of construction workers.

\subsubsection{FRBM setup}

The Mamdani-type fuzzy inference system was used to define the relationships between the inputs and outputs using the fuzzy logic toolbox in MATLAB (Mamdani, Assilian 1975; Pedrycz 1996). The input and output membership functions for this study were constructed based on the time distribution data collected in the field. Mixed membership functions with three linguistic constants were chosen to describe each input variable, namely: low (trapezoidal membership function (TzMF)), medium (triangular membership function (TMF)), and high (trapezoidal membership function (TzMF)). Five membership functions, namely very low (TzMF), low (TMF), medium (TMF), high (TMF), and very high (TzMF) were used to define the output (motivation). The membership functions used for the input and output variables are illustrated in Figures 2 (a)-(d).

The fuzzy operator "minimum" was applied as the "AND" function to combine the variables. Table 4 shows the verbal representation of all $27\left(=3^{\wedge} 3\right)$ rules developed to define the relationships between the inputs/ antecedents (worker distribution time) and the output/ consequent membership functions (motivation).

The rules were inferred from interviews with experts and construction project management professionals including 4 senior academic and project management professors, 4 senior construction managers with 10 years or more construction management work experience, and 5 graduate students with 5 years or more field experience in construction projects. All the experts had a bachelor or master degree in civil engineering and experience of working with carpentry labours. The experts were presented with the antecedents of all 27 rules and they were asked to specify the consequent of each rule, by choosing one output to each rule among five possible outputs: very low, low, medium, high or very high.

The rules were considered independent and no weightings were applied, which means no rule was emphasized as more important in respect to estimating the output. Implication was performed with the minimum function, and aggregation was performed with the maximum function. The centroid method was applied as a means of defuzzification of the output membership functions to determine a crisp set. a)

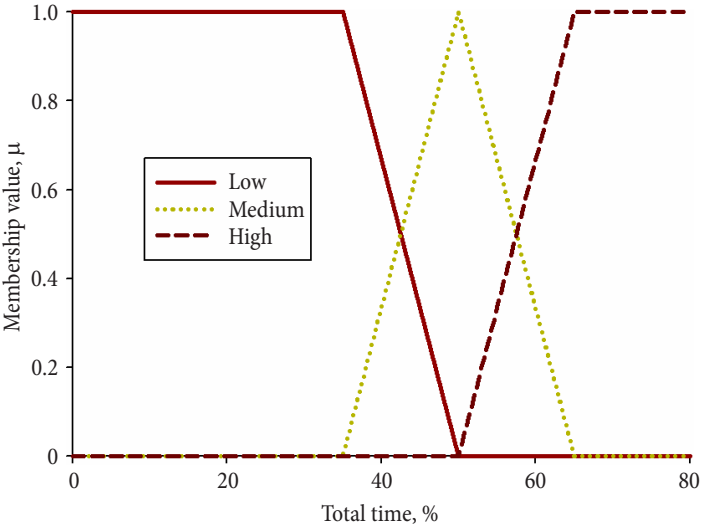

c)

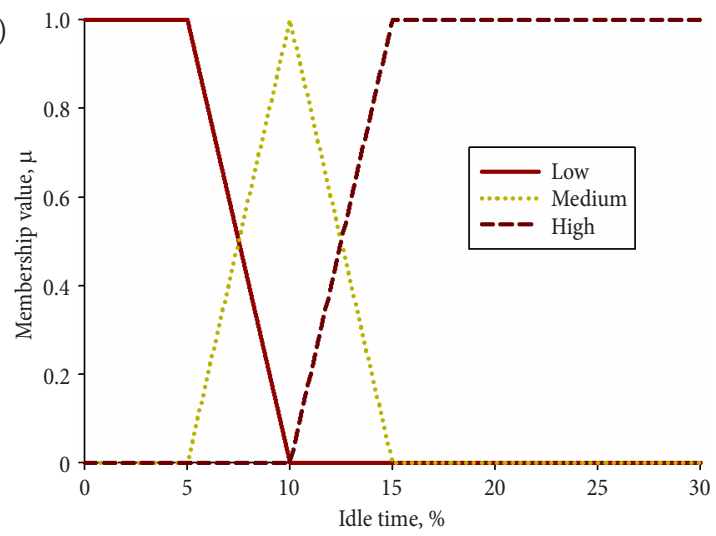

b)

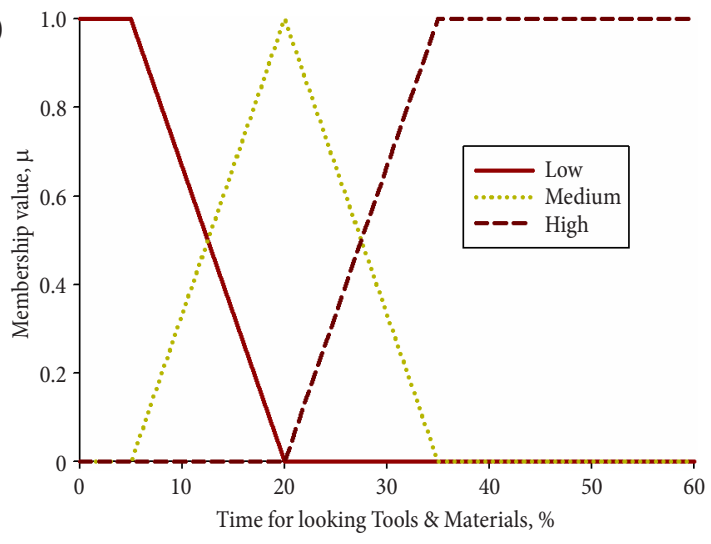

d)

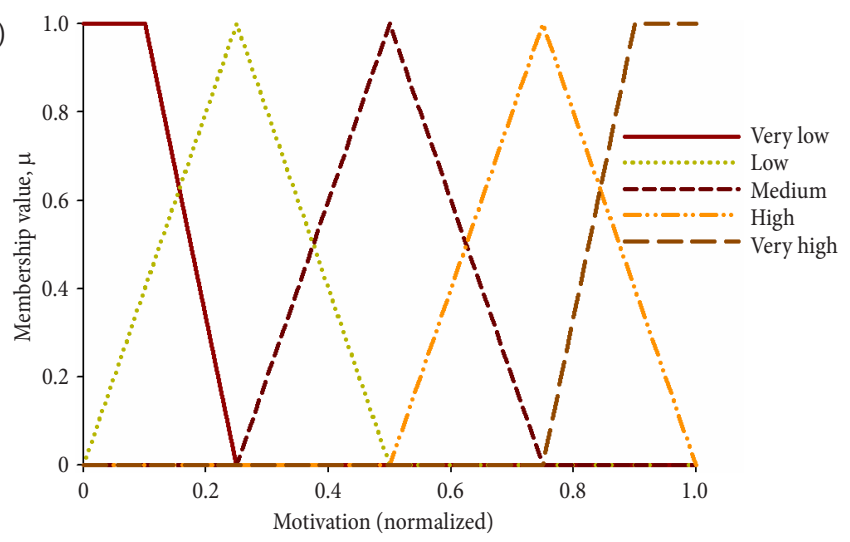

Fig. 2. Membership functions of input and output variables: (a) working (tool) time, (b) materials and tools searching time, (c) idle time, and (d) motivation 
Table 4. A rule set for predicting construction workers' motivation

\begin{tabular}{|c|c|c|c|c|c|c|c|c|}
\hline $\begin{array}{l}\# \\
\stackrel{0}{\Xi} \\
\stackrel{\Xi}{\Xi}\end{array}$ & $\leftrightarrows$ & 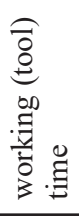 & $\vec{\Xi}$ & 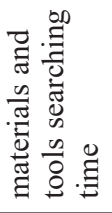 & $\vec{\Xi}$ & 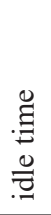 & $\begin{array}{l}\text { 巳 } \\
\stackrel{\Xi}{ \pm}\end{array}$ & 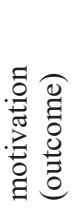 \\
\hline 1 & if & $L$ & and & $L$ & and & $L$ & then & $M$ \\
\hline 2 & if & $L$ & and & $L$ & and & $M$ & then & $L$ \\
\hline 3 & if & $L$ & and & $L$ & and & $H$ & then & $V L$ \\
\hline 4 & if & $L$ & and & $M$ & and & $L$ & then & $L$ \\
\hline 5 & if & $L$ & and & $M$ & and & $M$ & then & $L$ \\
\hline 6 & if & $L$ & and & $M$ & and & $H$ & then & $V L$ \\
\hline 7 & if & $L$ & and & $H$ & and & $L$ & then & $M$ \\
\hline 8 & if & $L$ & and & $H$ & and & $M$ & then & $L$ \\
\hline 9 & if & $L$ & and & $H$ & and & $H$ & then & $L$ \\
\hline 10 & if & $M$ & and & $L$ & and & $L$ & then & $M$ \\
\hline 11 & if & $M$ & and & $L$ & and & $M$ & then & $M$ \\
\hline 12 & if & $M$ & and & $L$ & and & $H$ & then & $L$ \\
\hline 13 & if & $M$ & and & $M$ & and & $L$ & then & $M$ \\
\hline 14 & if & $M$ & and & $M$ & and & $M$ & then & $M$ \\
\hline 15 & if & $M$ & and & $M$ & and & $H$ & then & $L$ \\
\hline 16 & if & $M$ & and & $H$ & and & $L$ & then & $M$ \\
\hline 17 & if & $M$ & and & $H$ & and & $M$ & then & $M$ \\
\hline 18 & if & $M$ & and & $H$ & and & $H$ & then & $L$ \\
\hline 19 & if & $H$ & and & $L$ & and & $L$ & then & $\mathrm{VH}$ \\
\hline 20 & if & $H$ & and & $L$ & and & $M$ & then & $H$ \\
\hline 21 & if & $H$ & and & $L$ & and & $H$ & then & $M$ \\
\hline 22 & if & $H$ & and & $M$ & and & $L$ & then & $H$ \\
\hline 23 & if & $H$ & and & $M$ & and & $M$ & then & $H$ \\
\hline 24 & if & $H$ & and & $M$ & and & $H$ & then & $M$ \\
\hline 25 & if & $H$ & and & $H$ & and & $L$ & then & $\mathrm{VH}$ \\
\hline 26 & if & $H$ & and & $H$ & and & $M$ & then & $H$ \\
\hline 27 & if & $H$ & and & $H$ & and & $H$ & then & $H$ \\
\hline
\end{tabular}

\section{Results and discussion}

Figure 3 shows the relationship between the motivation levels of 38 construction workers evaluated using the FRBM and the EIV model. The matching between the motivation values predicted by FRBM and the motivation values obtained from EIV are shown with the line of equity $(y=x)$. The figure clearly shows that the data from both methods are very close to the line for "medium" motivation ranges, indicating that both FRBM and EIV methods are in agreement to predict the motivation level of construction workers at and near the medium ranges. However, the two models failed to match for few construction workers with "extreme" motivation ranges, i.e. those with very low and very high motivation levels. For lower motivational ranges, the motivational values predicted by FRBM are generally higher than the motivational values obtained from EIV method. Contrarily, the motivational values predicted by FRBM are consist- ently lower than the motivational values obtained from EIV method for high motivational levels. This discrepancy at extreme ranges is most likely due to the phenomenon called the "extreme response bias" from Likert scale which subsequently affected the motivation values calculated using the EIV method. Extreme response bias refers to the tendency of making disproportionate use of the extreme ends of a Likert type response scale (e.g. strongly agree or strongly disagree).

Figure 4 shows the relationship between the motivation levels of 38 construction workers evaluated using the FRBM and the EIV model calculated using crisp or fuzzy-Likert scales. As it can be seen in Figure 4, the use of fuzzy-Likert scale for the EIV model slightly improves the extreme response bias. The use of truncated triangular fuzzy membership for extreme Likert scales (for 1 and 7) coupled with the ability of fuzzy system to capture the uncertainty of the workers' response helped to reduce the extreme response bias shown at extreme ranges of motivation values estimated using the EIV method.

The expectancy theory (EIV model) can be useful to construction managers to find out which rewards are seen as valuable by the employees, to create instrumentality that the accomplishments of certain tasks will generate the rewards valued by the employees, and to ensure that the employees have the necessary capabilities to accomplish the given task. However, the expectancy theory

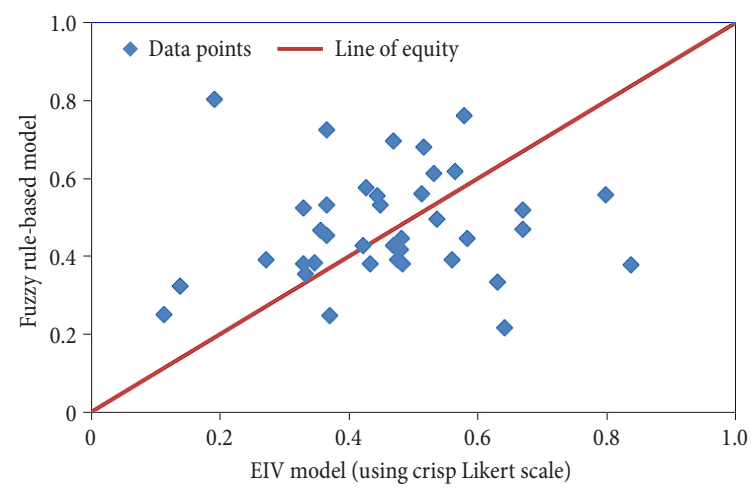

Fig. 3. Scatter plot of workers' motivation calculated using EIV method and fuzzy rule-based model

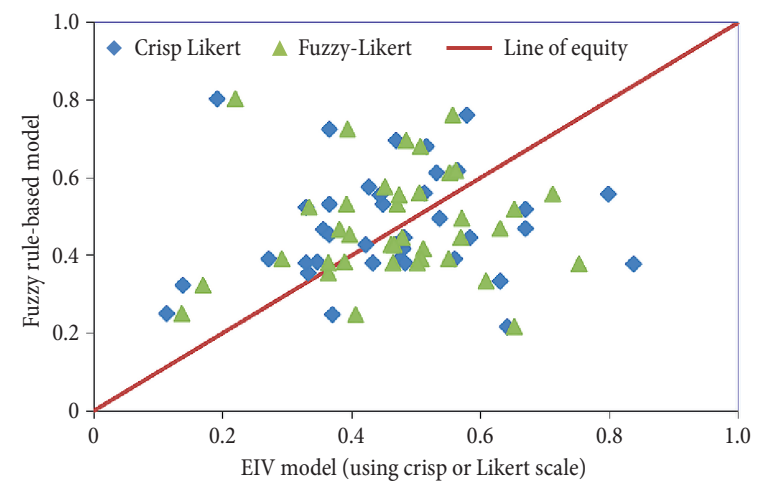

Fig. 4. Scatter plot of workers' motivation calculated using fuzzy rule-based model and Likert EIV or fuzzy-Likert EIV methods 
requires traditional methods of data collection system through questionnaire and interview survey techniques that are generally considered as labour-intensive, timeconsuming, and expensive.

The fuzzy rule-based model developed using easily measurable and observable worker time distribution data seems very practical and well suited to evaluate the overall motivational status of construction workers. The FRBM results matched well in the middle motivational ranges and gave more plausible results at the extreme motivation ranges compared to the traditional EIV estimates. The fuzzy rule-based system is also quite easy to develop and to understand compared to the traditional EIV model. It may be possible to further improve the FRBM performance by incorporating more input variables (work time distributions) in the expert system, changing shape or increasing the number of membership functions of input variables, introducing different weighting factors to the fuzzy expert rules, or modifying the relative contribution of the input variables to the overall motivation of the construction workers. Further research should also explore the effect of increasing data set (number of workers) and number of projects so that the FRBM model can be adopted for other construction disciplines and sectors.

\section{Conclusions}

A fuzzy rule-based model is proposed to determine the motivation levels of construction workers. The model was constructed on the basis of expert knowledge and observed worker time distribution data, i.e. working (tool) time (\%), searching for tools and materials time (\%), and idle time (\%). The motivational level of workers obtained by the fuzzy expert system is compared with the motivational levels calculated using the traditional expectancy theory (EIV) method. The results of fuzzy rule-based models were in good agreement with EIV model for the middle range motivation values. The fuzzy rule-based system is quite easy to develop and easy to understand compared to the traditional EIV model commonly used in performance evaluation.

Indeed the proposed fuzzy rule-based model used for carpentry construction workers can be easily transferred to analyze the motivational aspects of other workers involved in construction industries. However, in order to apply the same motivational evaluation analysis for workers of other industries with a very different work environment (e.g., Hotel or truism industry), further research will require identifying relevant motivational variables such as worker time variables.

There are indeed some limitations for different uncertainty modeling tools including fuzzy inference system. The main reason for selecting fuzzy inference system in this study is the measurement efficiency and simplicity based on fuzzy logic, comparing to analytical propagation methods that require complex mathematical expressions. In addition, fuzzy inference system can be implemented with limited data to handle different epistemic uncertainties (e.g. uncertainty due to subjective and objective measures, expert opinions, natural languages), in terms of degree of membership. This research designed to indicate and simplify the application of fuzzy rule-based model as a complement tool for EIV model and motivational analysis in construction industry. Aadditional research, development, and testing can be done to make it more comprehensive in addressing a wider range of factors and to make it more generalizable in nature.

\section{References}

Adams, J. S. 1963. Toward an understanding of inequity, Journal of Abnormal and Social Psychology 67: 422-463. http://dx.doi.org/10.1037/h0040968

Arditi, D. 1985. Construction productivity improvement, Journal of Construction Engineering \& Management 111(1): 1-14.

http://dx.doi.org/10.1061/(ASCE)0733-9364(1985)111:1(1)

Alderfer, C. 1969. An empirical test of a new theory of human needs, Organizational behavior and human performance 4(2): $142-175$.

http://dx.doi.org/10.1016/0030-5073(69)90004-X

Banik, G. 1999. Construction productivity improvement, in Proc. of the 35th Annual Conference, Associated Schools of Construction, 7-10 April, San Luis Obispo, California, $165-178$.

Bendaña, R.; Del Caño, A.; De la Cruz, M. P. 2008. Contractor selection: fuzzy control approach, Canadian Journal of Civil Engineering 35(5): 473-486. http://dx.doi.org/10.1139/L07-127

Bennett, S.; Franco, L. M.; Kanfer, R.; Stubblebine, P. 2001. The development of tools to measure the determinants and consequences of health worker motivation in developing countries, Partnerships for Health Reform, Major Applied Research 5. Technical Paper No. 2. Bethesda, MD.

Brehm, J. 1966. A theory of psychological reactance. New York: Academic Press.

Chang, N.; Chen, H.; Ning, S. 2001. Identification of river water quality using the fuzzy synthetic evaluation approach, Journal of Environmental Management 63(3): 293-305. http://dx.doi.org/10.1006/jema.2001.0483

Chiang, C.; Jang, S. 2008. An expectancy theory model for hotel employee motivation, International Journal of Hospitality Management 27(2): 313-322. http://dx.doi.org/10.1016/j.ijhm.2007.07.017

Choy, E.; Ruwanpura, J. Y. 2006. Predicting construction productivity using situation-based simulation models, Canadian Journal of Civil Engineering 33(12): 1585-1601. http://dx.doi.org/10.1139/106-088

Dai, J.; Goodrum, P.; Maloney, W. 2009. Construction craft workers' perceptions of the factors affecting their productivity, Journal of Construction Engineering and Management 135(3): 217-226.

http://dx.doi.org/10.1061/(ASCE)0733-9364(2009)135:3(217)

de Vries, B.; Steins, R. J. 2008. Assessing working conditions using fuzzy logic, Journal of Automation in Construction 17(5): 584-591. http://dx.doi.org/10.1016/j.autcon.2007.10.004

Dissanayake, M; Fayek, A. R. 2008. Soft computing approach to construction performance prediction and diagnosis, Canadian Journal of Civil Engineering 35(8): 764-776. http://dx.doi.org/10.1139/L08-023

Dongho, K. 2006. Employee motivation: just ask your employees, Seoul Journal of Busines 12(1): 19-36. 
Dubois, D.; Prade, H. 1980. Fuzzy sets and systems: theory and applications. New York: Academic Press.

Edwards, D.; Yang, J.; Wright, B. C.; Love, P. E. D. 2007. Establishing the link between plant operator performance and personal motivation, Journal of Engineering, Design and Technology 5(2): 173-187. http://dx.doi.org/10.1108/17260530710833211

Erinawati, R; Fenton, J. D. 2004. A comparison of computational intelligence systems for river flow forecasting, in Proc. of the $4^{\text {th }}$ Austral. Stream Management Conference, 19-22 October 2004, Launceston, Tasmania. Dept of Primary Industries, Water and Environment, Hobart. 217-222.

Fayek, A. R.; Flores, J. R. R. 2010. Application of fuzzy logic to quality assessment of infrastructure projects at conceptual cost estimating stage, Canadian Journal of Civil Engineering 37(8): 1137-1147. http://dx.doi.org/10.1139/L10-036

Fudge, R. S.; Schlacter, J. L. 1999. Motivating employees to act ethically: an expectancy theory approach, Journal of Business Ethics 18(3): 295-304. http://dx.doi.org/10.1023/A:1005801022353

Gallo, S.; Murino, T.; Santilllo, L. C. 1999. Time manufacturing prediction: preprocess model in neuro fuzzy expert system, in Proceedings of European Symposium on Intelligent Techniques [CD], 1999, Greece.

Gob R.; McCollin, C.; Ramalhoto, M. F. 2007. Ordinal methodology in the analysis of likert scales, Quality and Quantity 41(5): 601-626. http://dx.doi.org/10.1007/s11135-007-9089-z

Gorges, J.; Kandler, C. 2012. Adults' learning motivation: expectancy of success, value, and the role of affective memories, Learning and Individual Differences 22(5): 610 617. http://dx.doi.org/10.1016/j.lindif.2011.09.016

Guyonnet, D.; Côme, B.; Perrochet, P.; Parriaux, A. 1999. Comparing two methods for addressing uncertainty in risk assessments, Journal of Environmental Engineering 125(7): 660-666. http://dx.doi.org /10.1061/(ASCE)07339372(1999)125:7(660)

Hajkowicz, S.; Collins, K. 2007. A review of multiple criteria analysis for water resource planning and management, Water Resources Management 21(9): 1553-1566. http://dx.doi.org/10.1007/s11269-006-9112-5

Hanna, A.; Taylor, C.; Sullivan, K. 2005. Impact of extended overtime on construction labour productivity, Journal of Construction Engineering and Management 131(6): 734739.

http://dx.doi.org/10.1061/(ASCE)0733-9364(2005)131:6(734)

Herzberg, F.; Mausner, B.; Snyderman, B. 1959. The motivation to work. New York: Wiley.

Hewage, K. 2007. Construction productivity improvement by worker motivation and IT based communication. University of Calgary, Alberta, Canada.

Hewage, K.; Ruwanpura, J. Y. 2006. Carpentry workers issues and efficiencies related to construction productivity in commercial construction projects in Alberta, Canadian Journal of Civil Engineering 33(8): 1075-1089. http://dx.doi.org/10.1139/106-050

Hewage, K.; Ruwanpura, J. Y. 2009. A novel solution for construction on-site communication-the information booth, Canadian Journal of Civil Engineering 36(4): 659-671. http://dx.doi.org/10.1139/L09-026

Hu, H.-Y.; Lee, Y.-C.; Yen, T.-M. 2010. Service quality gaps analysis based on Fuzzy linguistic SERVQUAL with a case study in hospital out-patient services, The TQM Journal 22(5): 499-515. http://dx.doi.org/10.1108/17542731011072847

Huitt, W. 2004. Maslow's hierarchy of needs, Educational psychology interactive. Valdosta State University.
Hwang, S.; Liu, L. 2010. Contemporaneous time series and forecasting methodologies for predicting short-term productivity, Journal of Construction Engineering and Management 136(9): 1047-1055.

http://dx.doi.org/10.1061/(ASCE)CO.1943-7862.0000183

Islam, N.; Sadiq, R.; Rodriguezb, M. J.; Francisque, A. 2013. Evaluation of source water protection strategies: a fuzzybased model, Journal of Environmental Management 121(30): 191-201. http://dx.doi.org/10.1016/j.jenvman.2013.02.022

Jang, J. S. R.; Sun, C. T.; Mizutani, E. 1997. Neuro-fuzzy and soft computing: a computational approach to learning and machine intelligence. New Jersey: Prentice-Hall International, Inc.

Jaramillo, M.; González, D. 2009. Integrated air quality index for Colombian cities, Revista Facultad De Ingenieria-Universidad De Antioquia 48: 97-106.

Jenkins, J. R.; Douglas, G.;Laufer, A.; 1982. Improving construction productivity: the case for motivation, $A A C E$ Transactions. AACE International, Morgantown, USA.

Jergeas, G.; Ruwanpura, J. 2009. Why cost and schedule overruns on mega oil sands projects?, Practice Periodical on Structural Design and Construction 15(1): 40-43. http://dx.doi.org/10.1061/(ASCE)SC.1943-5576.0000024

Klir, G.; Yuan, B. 1995. Fuzzy sets and fuzzy logic: theory and applications. New Jersey: Prentice Hall., Prentice Hall International, Upper Saddle River. 592 p.

Kominis, G.; Emmanuel, C. 2007. The expectancy-valence theory revisited: developing an extended model of managerial motivation, Management Accounting Research 18(1): 49-75. http://dx.doi.org/10.1016/j.mar.2006.10.002

Kramer, E.; Cavero, D.; Stamer, E.; Krieter, J.; 2009. Mastitis and lameness detection in dairy cows by application of fuzzy logic, Livestock Science 125 (1): 92-96. http://dx.doi.org/10.1016/j.livsci.2009.02.020

Kumar, M.; Thurow, K.; Stoll, N.; Stoll, R. 2007. Robust fuzzy mappings for QSAR studies, European Journal of Medicinal Chemistry 42(5): 675-685.

http://dx.doi.org/10.1016/j.ejmech.2006.12.017

Kusan, H.; Aytekin, O.; Özdemir, I. 2010. The use of fuzzy logic in predicting house selling price, Expert Systems with Applications 37(3): 1808-1813. http://dox.doi.org/ doi:10.1016/j.eswa.2009.07.031

Kvanli, A. H.; Pavur, R. J.; Guynes, C. S. 2000. Introduction to business statistics. $5^{\text {th }}$ ed. Cincinnati, $\mathrm{OH}$ : South-Western College Publishing.

Lalla, M.; Facchinetti, G.; Mastroleo, G. 2004. Ordinal scales and fuzzy set systems to measure agreement: an application to the evaluation of teaching activity, Quality and Quantity 38(5): 577-601. http://dx.doi.org/10.1007/s11135-005-8103-6

Lam, S.; Tang, C. 2003. Motivation of survey employees in construction projects, Journal of Geospatial Engineering 5(1): 6-61.

Latham, G.; Pinder, C. 2005. Work motivation theory and research at the dawn of the twenty-first century, Annual Revew Psychology 56: 485-516. http://dx.doi.org/10.1146/annurev.psych.55.090902.142105

Lermontov, A.; Yokoyama, L. 2009. River quality analysis using fuzzy water quality index: ribeira do Iguape river watershed, Brazil, Ecological Indicators 9(6): 1188-1197. http://dx.doi.org/10.1016/j.ecolind.2009.02.006

Locke, E. 1968. Toward a theory of task motivation and incentives, Organizational Behavior and Human Performance 3: $157-189$. http://dx.doi.org/10.1016/0030-5073(68)90004-4 
Love, P.; Edwards, D.; Smith, J. 2005. A forensic examination of the causal mechanisms of rework in a structural steel supply chain, Managerial Auditing Journal 20(5): 187-197.

Lyons, T.; Skitmore, M. 2004. Project risk management in the Queensland engineering construction industry: a survey, International Journal of Project Management 22: 51-61. http://dx.doi.org/10.1016/S0263-7863(03)00005-X

Maloney, W.; McFillen, J. 1986. Motivation in unionized construction, Journal of construction engineering and Management 112(1): 122-135.

http://dx.doi.org/10.1061/(ASCE)0733-9364(1986)112:1(122)

Maloney, W.; McFillen, J. 1987. Motivational impact of work crews, Journal of Construction Engineering and Management 113(2): 208-221. http://dx.doi.org/10.1061/ (ASCE)0733-9364(1987)113:2(208)

Mamdani, E. H.; Assilian, S. 1975. An experiment in linguistic synthesis with a fuzzy logic controller, International Journal of Man-Machine Studies 7(1): 1-13. http://dx.doi.org/10.1016/S0020-7373(75)80002-2

Mangione, T. W. 1995. Mailed survey: improving the quality. California, U.S.: Sage Publications Ltd. http://dx.doi.org/10.4135/9781412984881

Mansfield, N. R.; Odeh, N. S. 1991. Issues affecting motivation on construction projects, International Journal of Project Management 9(2): 93-98. http://dx.doi.org/10.1016/0263-7863(91)90067-6

Maslow, A. 1943. A theory of human motivation, Psychological review 50: 370-96. http://dx.doi.org/10.1037/h0054346

Mason, A. K.; Kahn, D. J. 1997. Estimating costs with fuzzy logic, AACE International Transactions, EST.03.1EST.03.6.

McGregor, D. 1960. The human side of enterprise. New York: McGraw-Hill. 246 p.

Nasirzadeh, F.; Afshar, A.; Khanzadi, M. 2008. Dynamic risk analysis in construction projects, Canadian Journal of Civil Engineering 35(8): 820-831. http://dx.doi.org/10.1139/L08-035

Nasirzadeh, F.; Nojedehi, P. 2012. Dynamic modeling of labour productivity in construction projects, International Journal of Project Management 31(6): 903-911. http://dx.doi.org/10.1016/j.ijproman.2012.11.003

Ng, S.; Skitmore, R.; Lam, K.; Poon, A. 2004. Demotivating factors influencing the productivity of civil engineering projects, International Journal of Project Management 31(6): 903-911.

Olomolaiye, P. O.; Price, A. D. F. 1989. A review of construction operative motivation, Building and Environment 24(3): 279287. http://dx.doi.org/10.1016/0360-1323(89)90042-5

Ouchi, W. 1981. Theory z. New York: Avon.

Pedrycz, W. (Ed.). 1996. Fuzzy modelling: paradigms and practice. Dordrecht: Kluwer Academic Press. http://dx.doi.org/10.1007/978-1-4613-1365-6

Price, A.; Bryman, A.; Dainty, A. 2004. Empowerment as a strategy for improving construction performance, Leadership Management and Engineering 4(1): 27-37: http://dx.doi.org/10.1061/(ASCE)1532-6748(2004)4:1(27)

Rihani, R.; Bensmaili, A.; Legrand, J. 2009. Fuzzy logic modelling tracer response in milli torus reactor under aerated and non-aerated conditions, Chemical Engineering Journal 152: 566-574.

http://dx.doi.org/10.1016/j.cej.2009.05.025

Rose, T.; Manley, K. 2011. Motivation toward financial incentive goals on construction projects, Journal of Business Research 64(7): 765-773. http://dx.doi.org/10.1016/j.jbusres.2010.07.003

Ross, T. J. 1995. Fuzzy logic with engineering applications. New York, NY: McGraw Hill Co.
Ross, T. 2004. Fuzzy logic with engineering applications. Hoboken, NJ: Wiley.

Sadiq, R.; Al-Zahrani, A. M.; Sheikh, A. K.; Husain, T.; Farooq, S. 2004. Performance evaluation of slow sand filters using fuzzy rule-based modelling, Environmental Modelling and Software 19(5): 507-515. http://dx.doi.org/10.1016/S1364-8152(03)00165-8

Shaheen, A.; Fayek, A. R.; Abourizk, S. M. 2007. Fuzzy numbers in cost range estimating, Journal of Construction Engineering and Management 133(4): 325-334.

http://dx.doi.org/10.1061/(ASCE)0733-9364(2007)133:4(325)

Skinner, B. 1969. Contingencies of reinforcement. New York: Appleton-Century-Crofts.

Song, L.; AbouRizk, S. 2008. Measuring and modeling labour productivity using historical data, Journal of Construction Engineering and Management 134(10): 786-794.

http://dx.doi.org/10.1061/(ASCE)0733-9364(2008)134:10(786)

Tah, J. H. M.; Carr, V. 2000. A proposal for construction project risk assessment using fuzzy logic, Journal of Construction Management and Economics 18: 491-500. http://dx.doi.org/10.1080/01446190050024905

Trochim, W.; Donnelly, J. P. 2007. The research methods knowledge base. $3^{\text {rd }}$ ed. Mason, $\mathrm{OH}$ : Thomson Publishing.

Tsaur, S.; Chang, T.; Yen, C. 2000. The evaluation of airline service quality by fuzzy MCDM, Tourism Management 23(2): 107-115. http://dx.doi.org/10.1016/S0261-5177(01)00050-4

Vroom, V. 1964. Work and motivation. New York: Wiley.

Warren, R. H. 1989. Motivation and productivity in the construction industry. New York: Van Nostrand Reinhold. 266 p. http://dx.doi.org/10.1007/978-1-4684-8827-2

Welkowitz, J.; Cohen, B. H.; Ewen, R. B. 2006. Introductory statistics for the behavioral sciences. $6^{\text {th }}$ ed. Hoboken, NJ: John Wiley and Sons.

Westover, J. H.; Westover, A. R.; Westover, A. L. 2010. Enhancing long-term worker productivity and performance, International Journal of Productivity and Performance Management 59(4): 372-387. http://dx.doi.org/10.1108/17410401011038919

Zadeh, L. 1965. Fuzzy sets, Information and Control 8(3): 338353. http://dx.doi.org/10.1016/S0019-9958(65)90241-X

Zhou, Y. 2004. Motivation, performance and job satisfaction of construction management professionals $(C M P S)$. University of Calgary, Canada.

\section{Appendix}

Sample validity and reliability of research tools are key pre-requisites in social science research methods. All the data analysis and conclusions are dependent on the degree of satisfaction of these concepts. It is possible to determine the degree of accuracy of the conclusions formulated with the data from the questionnaire surveys and interviews. In this study central limit theorem was used for sample size validity.

The central limit theorem in statistics indicates that “obtaining large samples (generally sample size $>30$ ) from any population, the sample mean will follow an approximate normal distribution" (Kvanli et al. 2000). Welkowitz et al. (2006) presented Eqn (A-1) for sample size calculations in social sciences:

$$
n=\left[z_{\alpha / 2} \sigma / d\right]^{2}
$$

when the $n>30$,

where: $n$ - Sample size; $d$ - Desired error margin; 
$1-\alpha-$ Probability associated with the error margin; $\sigma-$ Standard deviation of results.

In the current study, an initial pilot study ${ }^{1}$ of 3 months with carpentry workers revealed that the standard deviation of working time is $15.4 \%$. Initially the observations were planned for an error margin of 3\% with $90 \%$ certainty. This was based on the level of accuracy experienced (variance experienced) during the pilot study observations where three researchers observed the same subject.

Then:

$d=3 \%$;

$1-\alpha=90 \%$ certainty with the error estimation; then $\alpha=0.05=15.4 \%$;

Based on the Eqn (A-1), the calculations are as follows;

$n=\left[z_{0.05} \times 0.154 / 0.03\right]^{2}$, where $z_{0.05}=1.645$.

Therefore $n=72$.

Based on the above analysis, at least 72 observations were needed to draw conclusions with $90 \%$ certainty. Therefore, it was planned to observe 101 workers (more than 72) in actual construction settings, with an a.m. observation, an interview, the presentation of the

\footnotetext{
${ }^{1}$ In this research, initially, a pilot survey was conducted. Two research assistants and one of the authors made the observations. During the pilot study, direct and work sampling methods of observations were tested. The three observers analysed and discussed the variations in the collected data.
}

questionnaire, a p.m. observation and then collect the completed questionnaire at a later date. Answering to the questionnaire survey was optional in order to assure the truthfulness of the survey responses.

Workers returned 39 questionnaires (out of 101) where all the questions were rated on a 1-7 Likert scale (48 questions). The average standard deviation of all the ratings was 1.28 out of 7 . Using above equation:

$39=[z 0.05 \times 1.28 / d] 2$, where $z 0.05=1.645$.

Therefore $d=0.337$ out of 7 .

The 39 returned questionnaire surveys are statistically valid and the conclusions drawn are valid with \pm 0.337 variation with $90 \%$ certainty.

In addition, 101 workers were interviewed and some of the interview questions were also rated on a 1-7 Likert scale. Open-ended questions were another component of the interviews. The standard deviation for the responses to the questions with a Likert scale was 1.39. Using above equation:

$$
101=\left[z_{0.05} \times 1.39 / d\right]^{2}, \text { where } z_{0.05}=1.645,
$$

Therefore $d=0.228$.

The responses to the Likert scale interview questions are valid to draw conclusions with \pm 0.228 variation with $90 \%$ certainty.

Muluken YEHEYIS. Dr Yeheyis worked as the post-doctoral fellow at the University of British Columbia, Okanagan campus. At present, Dr. Yeheyis works as a water resources engineer in Hatfield Consultants, Vancouver, Canada. Dr Yeheyis is an expert in water resources and environmental modelling.

Bahareh REZA. Dr Reza is a postdoctoral fellow at the University of British Columbia, School of Engineering. Her research interests are in sustainability appraisal of infrastructure assets, developing advanced life cycle sustainability assessment approaches (e.g. emergy-based LCA), developing low-impact development solutions, multi-criteria decision making (MCDM) in the infrastructure system, and developing effective and sustainable asset management strategies.

Kasun HEWAGE. Dr Kasun Hewage is an Associate Professor at the School of Engineering, University of British Columbia, Okanagan campus. He is a professional engineer with multi-disciplinary project experiences. Dr Hewage has been leading several research projects in lifecycle assessment, green construction, construction productivity, and sustainability.

Janaka Y. RUWANPURA. Dr Ruwanpura is the Vice-Provost (International) at the University of Calgary. Prior to this role, he has been a Professor and the Canada Research Chair in Project Management Systems in the Schulich School of Engineering at the University of Calgary, Canada. He is the Founding Director of the Centre for Project Management Excellence at the University of Calgary.

Rehan SADIQ. Dr Sadiq is a Professor at the School of Engineering, University of British Columbia, Okanagan campus. He has been involved in research related to drinking water quality modelling, environmental risk assessment and decision-making, and asset management of civil infrastructure systems. 